\title{
dspace.vutbr.cz
}

\section{Electronically Reconfigurable Universal Filter Based on VDTAs}

\author{
LANGHAMMER, L.; ŠOTNER, R.; DOMANSKÝ, O.; HRICKO, T.
}

Proceedings of the 2018 28th International Conference Radioelektronika (RADIOELEKTRONIKA)

pp. 1-4

elSBN: 978-1-5386-2485-2

DOI: http://dx.doi.org/10.1109/RADIOELEK.2018.8376353

Accepted manuscript

(C2018 IEEE. Personal use of this material is permitted. Permission from IEEE must be obtained for all other uses, in any current or future media, including reprinting/republishing this material for advertising or promotional purposes, creating new collective works, for resale or redistribution to servers or lists, or reuse of any copyrighted component of this work in other works. Lukas Langhammer, Roman Sotner, Ondrej Domansky, Tomas Hricko „Electronically Reconfigurable Universal Filter Based on VDTAs", Proceedings of the 2018 28th International Conference Radioelektronika (RADIOELEKTRONIKA), pp. 1-4, 2018. DOI: 10.1109/RADIOELEK.2018.8376353. Final version is available at https://ieeexplore.ieee.org/document/8376353/ 


\title{
Electronically Reconfigurable Universal Filter Based on VDTAs
}

\author{
Lukas Langhammer, Roman Sotner, Ondrej Domansky, Tomas Hricko \\ Department of Radio Electronics, Faculty of Electrical Engineering and Communication \\ Brno University of Technology \\ Technicka 12, 61600, Brno, Czech Republic \\ langhammer@phd.feec.vutbr.cz
}

\begin{abstract}
The proposed filter extends features of the previously presented Voltage Differencing Transconductance Amplifiers (VDTAs)-based frequency filter. It brings the new advantage of an electronic reconfiguration of its transfer. The proposed structure provides reconnection-less change between low-pass, band-pass, high-pass, band-stop and all-pass transfer functions. The electronic control of the filter parameters such as the pole frequency and quality factor remain preserved. The theoretical assumptions are supported by PSpice simulations using transistor-level models.
\end{abstract}

Keywords—adjustable current amplifer; electronic control; electronic reconfiguration; universal filter; voltage differencing transconductance amplifier

\section{INTRODUCTION}

The ever-increasing demands on features of active frequency filters lead to the design of new filtering structures with enhanced properties such as electronic control of desired filter characteristic (pole frequency, quality factor, level of pass-band/stop-band region), wider bandwidth range, or availability of multiple, if not all, standard transfer functions (low pass (LP), band pass (BP), high pass (HP), band stop (BS) and all pass (AP)).

Despite of a useful offer of universal filters [1-9], or multifunctional filters [10] to provide some if not all standard functions, these structures usually have several inputs or outputs when manual reconnection of particular input/output is necessary to change type of the transfer function. The structures, depending on the number of inputs/outputs, can be referred to as Single-Input MultipleOutput (SIMO) filters [1-4], [10], Multiple-Input SingleOutput (MISO) filters [5-8], or we can come across SingleInput Single-Output (SISO) filtering structures [9] when modification of the circuit structure is required to change type of the function. The manual reconnection is not suitable or even possible in some cases, on-chip implementation of given structure, for example. The manual reconnection could be implemented by complementing the filtering structure with controllable switches, for instance. Nonetheless, this might bring some undesired features (requirements for the additional digital control (power consumption and chip area), interference of the clock signal with processed signal, etc.).

Other, more advantageous approach is implementing filtering structures which provide possibility of the electronic reconfiguration of their transfer [11-15]. The resulting transfer function of these structures is based on the setting of controllable parameters of used active elements suitably placed in the circuit structure. Paper [11] presents an electronically reconfigurable filter using Z-Copy Controlled Gain Voltage Differencing Current Conveyor (ZCCG-VDCC) utilizing the intrinsic resistance $R_{\mathrm{x}}$ to change between AP and LP function. Similarly, filter in paper [12] can provide AP and LP function by change of current gain $B$ and intrinsic resistance $R_{\mathrm{x}}$. This filter uses operational transconductance amplifiers (OTAs) and electronically controllable current conveyor of second generation (ECCII). Filtering structures in [13-15] are based on OTAs and can offer all standard transfer functions by adjustment of individual transconductances $g_{\mathrm{m}}$.

The filter proposed in this paper is designed using two Voltage Differencing Transconductance Amplifiers (VDTAs), three Adjustable Current Amplifiers (ACAs) and one auxiliary Multi-Output Current Follower (MO-CF). The filter can provide all standard transfer functions from the same circuit topology without necessity of physical reconnection by adjustment of current gains of used ACAs. Transconductances of VDTA elements are used in order to provide the electronic control of the pole frequency and quality factor independently on each other.

\section{FILTER PROPOSAL}

The proposed filter follows up on the previously published universal filter presented in [16]. The structure from [16] is based on two VDTAs and can provide all standard transfer functions (LP, BP, HP, BS, AP) and special transfers so-called high-pass with zero and low-pass with zero. The given filter is of Three-Input Single-Output (TISO) type when manual physical reconnection of particular input (or suitable combination of two or more inputs) is necessary in order to obtain desired transfer function. The schematic symbol of VDTA elements and its implementation using two OTAs are depicted in Fig. 1. The behavior of VDTA can be described by the matrix (1). The proposed filter results from the filtering structure in [16] which is complemented by suitably arrangement of three ACAs (which are used to change the filter transfer electronically) and one auxiliary MO-CF (distributing the input current). 

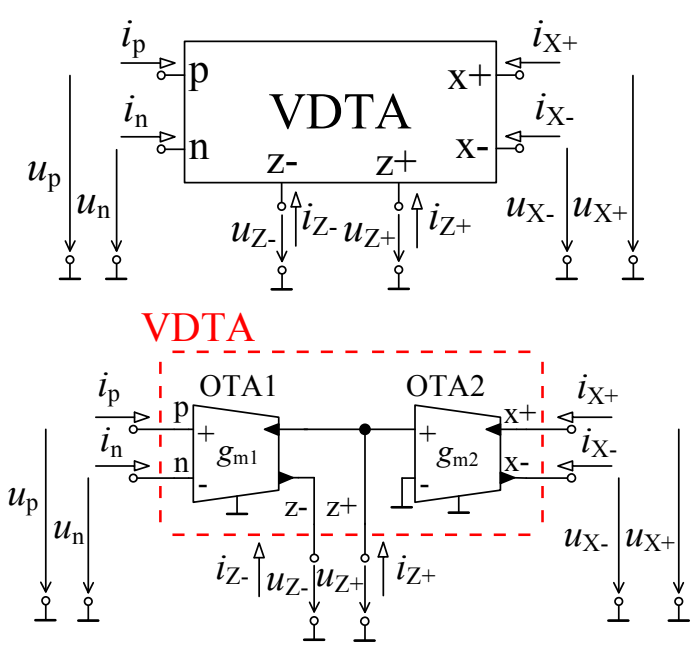

Fig. 1. Voltage Differencing Transconductance Amplifier schematic symbol (top), implementation using two OTAs (bottom)

$$
\left[\begin{array}{c}
i_{p} \\
i_{n} \\
i_{Z+} \\
i_{Z-} \\
i_{X+} \\
i_{X-}
\end{array}\right]=\left[\begin{array}{cccc}
0 & 0 & 0 & 0 \\
0 & 0 & 0 & 0 \\
g_{m 1} & -g_{m 1} & 0 & 0 \\
-g_{m 1} & g_{m 1} & 0 & 0 \\
0 & 0 & g_{m 2} & 0 \\
0 & 0 & -g_{m 2} & 0
\end{array}\right] \cdot\left[\begin{array}{c}
v_{p} \\
v_{n} \\
v_{Z+} \\
v_{Z-}
\end{array}\right]
$$

The schematic symbols of the ACA and MO-CF elements are presented in Fig. 2 a), b), respectively. The ACA element can be described by following equation: $i_{\text {OUT }}=B \cdot i_{\mathrm{IN}}$, where $B$ is the current gain of this element. The behavior of the MO-CF element is given as $i_{\mathrm{OUT} \pm}= \pm i_{\mathrm{IN}}$.
ACA

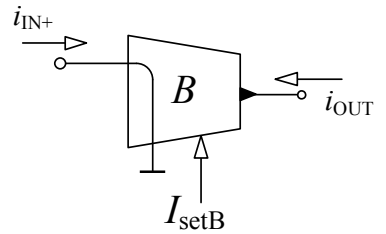

a)

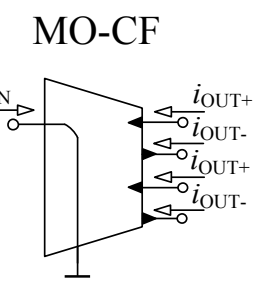

b)
Fig. 2. Schematic symbol: a) Adjustable Current Amplifier (ACA), b) MultiOutput Current Follower (MO-CF).

The resulting structure of the proposed filter electronically reconfigurable filter consisting of two VDTAs, three ACAs and one MO-CF is presented in Fig. 3. The transfer of the proposed filter is given as:

$$
\frac{\boldsymbol{I}_{O U T}}{\boldsymbol{I}_{I N}}=\frac{N(\boldsymbol{s})}{D(\boldsymbol{s})},
$$

where

$$
\begin{aligned}
& D(s)=s^{2} C_{1} C_{2} G_{1} G_{2}+s C_{2} g_{m 2} g_{m 3} g_{m 4}+ \\
& +G_{2} g_{m 1} g_{m 2} g_{m 3} \\
& N(s)=s^{2} C_{1} C_{2} G_{2} g_{m 3} B_{1}-s C_{2} g_{m 2} g_{m 3} g_{m 4} B_{3}+ \\
& +G_{2} g_{m 1} g_{m 2} g_{m 3} B_{2}
\end{aligned}
$$

From previous equations (2), (3) and (4) it is evident that the resulting transfer of the proposed filter can be controlled by setting of individual current gains $B_{1}-B_{3}$. Depending on actual setting of current gains, the proposed filter can provide following transfer functions:

- High-pass function for $B_{1}=1, B_{2}=B_{3}=0$,

- Low-pass function for $B_{2}=1, B_{1}=B_{3}=0$,

- Band-pass function for $B_{3}=1, B_{1}=B_{2}=0$,

- Band-stop function for $B_{1}=B_{2}=1, B_{3}=0$,

- All-pass function for $B_{1}=B_{2}=B_{3}=1$,

- High-pass function with zero for $B_{1}=1,0<B_{2}<1, B_{3}$ $=0$,

- Low-pass function with zero for $B_{2}=1,0<B_{1}<1, B_{3}$ $=0$.

The pole frequency $f_{0}$ and quality factor $Q$ of the proposed filter are expressed by following relations:

$$
f_{0}=\frac{1}{2 \pi} \sqrt{\frac{g_{m 1} g_{m 2} g_{m 3}}{C_{1} C_{2} G_{1}}}, \quad Q=\frac{G_{2}}{g_{m 4}} \sqrt{\frac{g_{m 1} C_{1} G_{1}}{g_{m 2} g_{m 3} C_{2}}}
$$

From relations in (5) can be seen that $f_{0}$ can be electronically controlled independently from Q by simultaneous change of transconductance $g_{\mathrm{m} 1}$ and $g_{\mathrm{m} 2}$ when a simple condition $g_{\mathrm{m} 1}=g_{\mathrm{m} 2}$ is applied. The quality factor can be controlled electronically without disturbing $f_{0}$ by adjustment of transconductance $g_{\mathrm{m} 4}$. Similarly, $f_{0}$ could be also controlled by change of values of capacitances $C_{1}, C_{2}$ and $\mathrm{Q}$ could be controlled by conductance $G_{2}$, but direct (immediate) ability of the electronic control is more advantageous.

\section{Simulations}

The proposal has been verified by PSpice simulations using transistor-level models of used active elements. The transistor-level model of the OTA element has been taken from [17]. The transconductance of OTA is controlled by DC current in this particular case. The used transistor-level model of the ACA element can be found in [18]. Current 


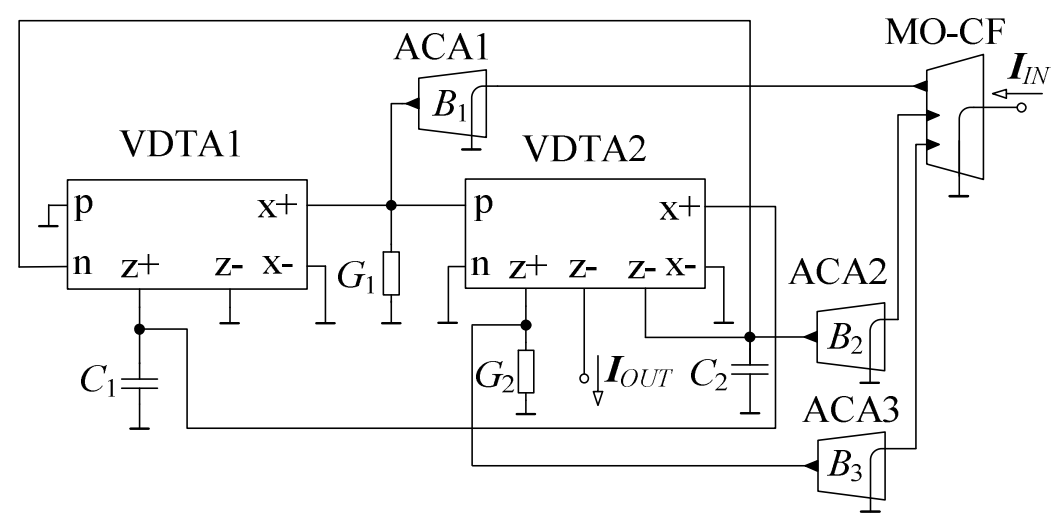

Fig. 3. Proposed electronically reconfigurable universal filter.

gain of this particular CMOS implementation of the ACA model is controlled by DC current. The transistorlevel model of the MO-CF element has been taken from [16]. All these models are implemented in $0.18 \mu \mathrm{m}$ TSMC CMOS technology with supply voltage equal to \pm 1 VThe proposed filter has been designed to operate at pole frequency equal to $100 \mathrm{kHz}$ and quality factor equal to 0.707 (Butterworth approximation). Based on these values, the values of transconductances and values of passive elements have been selected as follows: $g_{\mathrm{m} 1}=g_{\mathrm{m} 2}$ $=g_{\mathrm{m} 3}=1 \mathrm{mS}$, conductances $G_{1}=G_{2}=1 \mathrm{mS}$. Capacitances $C_{1}$ and $C_{2}(1.6 \mathrm{nF})$ were calculated from (5) in order to obtain the desired $f_{0}$. Transconductance $g_{\mathrm{m} 4}$ was set to $1.414 \mathrm{mS}$ resulting in $Q=0.707$.

Figure 4 shows output responses LP (blue line), BP (red line), HP (green line) and BS (magenta line) in case of simulations and compares them with the theoretical expectations (black dashed lines). The differences between the simulations and theory at lower and higher frequencies are due to the real features of used models of individual active elements. That applies for all simulation results presented in the paper.

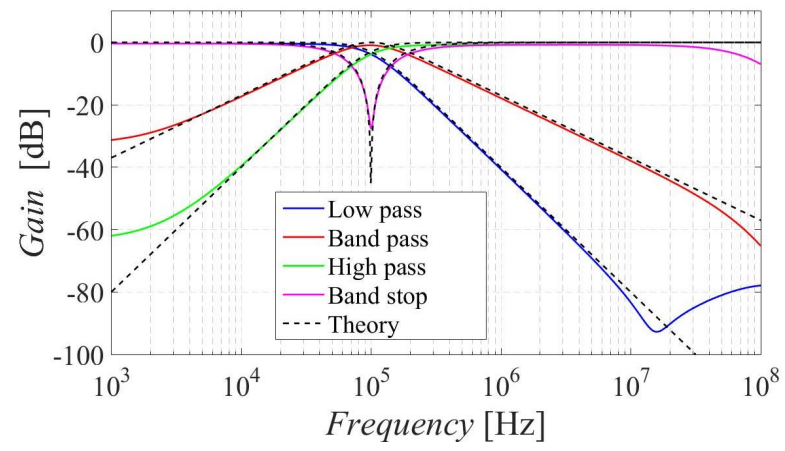

Fig. 4. Output responses LP, BP, HP and BS: theory (black dashed lines) and simulations (colored lines).

Characteristics of group delay, phase and gain of the AP filter are illustrated in Fig. 5. Phase (blue line), group delay (red line), gain (green line) are compared with the theory (black dashed lines). From the characteristic of gain it can be seen that the AP filter is suitable up to approximately $60 \mathrm{MHz}$.
The ability of the electronic control of $f_{0}$ is demonstrated in Fig. 6 for LP function and for three different settings of $g_{\mathrm{m} 1}, g_{\mathrm{m} 2}(0.5 \mathrm{mS}, 1 \mathrm{mS}$ and $2 \mathrm{mS})$ when $g_{\mathrm{m} 1}=g_{\mathrm{m} 2}=g_{\mathrm{m}}$. The values of $f_{0}$ for these selected values of transconductances $g_{\mathrm{m} 1}, g_{\mathrm{m} 2}$ are approximately $50 \mathrm{kHz}$, $100 \mathrm{kHz}$ and $200 \mathrm{kHz}$. Values obtained from simulations are stated in the graph legend (values in brackets). It can be seen that higher values of $f_{0}$ are closer to the theoretical expectations nevertheless, all results obtained from simulations are in good agreement with the theory.

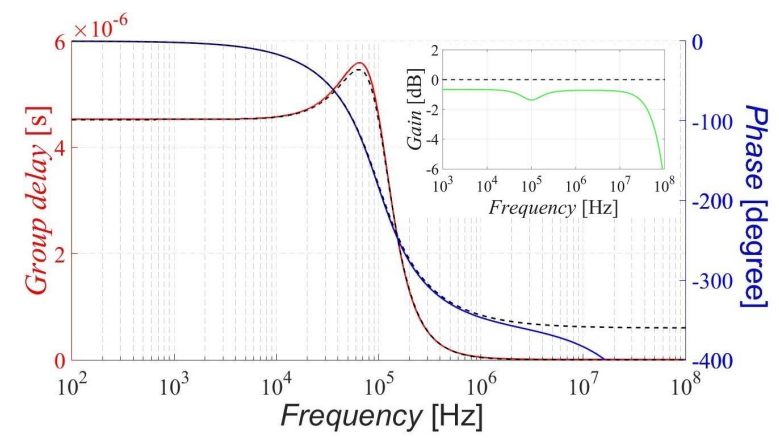

Fig. 5. Output responses of AP filter: phase (blue line), group delay (red line), gain (green line), theory (black dashed lines).

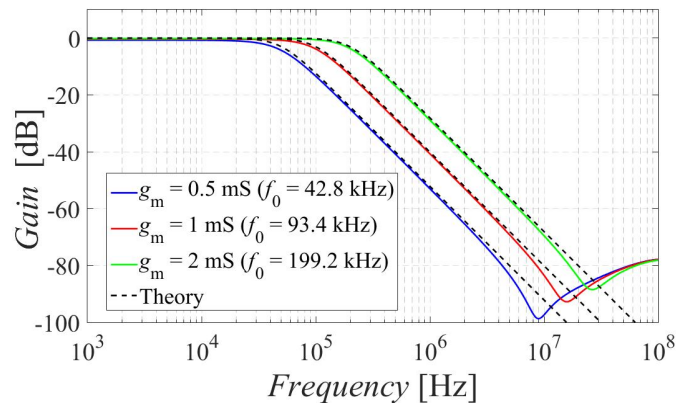

Fig. 6. Illustration of the electronic control of the pole frequency of LP for $f_{0}=50 \mathrm{kHz}, 100 \mathrm{kHz}$ and $200 \mathrm{kHz}$.

As mentioned before, it is also possible to electronically control the quality factor of the filter (independently on the pole frequency). Figure 7 illustrates this ability using BP function as an example. The values of $g_{\mathrm{m} 4}$ were set 
to $1.414 \mathrm{mS}, 0.707 \mathrm{mS}$ and $0.354 \mathrm{mS}$ which results in $Q$ equal to $0.71,1.41$ and 2.83. Values obtained from simulations are stated in the graph legend (values in brackets). The values of $Q$ show increasing difference between the simulation and theory as the value of $Q$ rises. Despite this fact, the obtained results are relatively close to the theory.

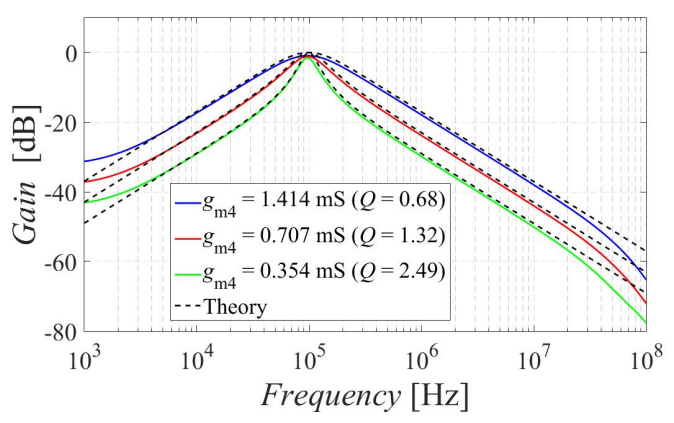

Fig. 7. Illustration of the electronic control of the quality factor of BP for $Q=0.71,1.41$ and 2.83 .

The proposed structure, thanks to its realization, also offers the ability to obtain low-pass and high-pass response with intended zero in transfer function (LPZ, HPZ). These types of functions can be used in special cases due to their feature to provide steeper transition from passband to stopband area [19]. The behavior of the LPZ and HPZ function can be observed in Fig. 8 .

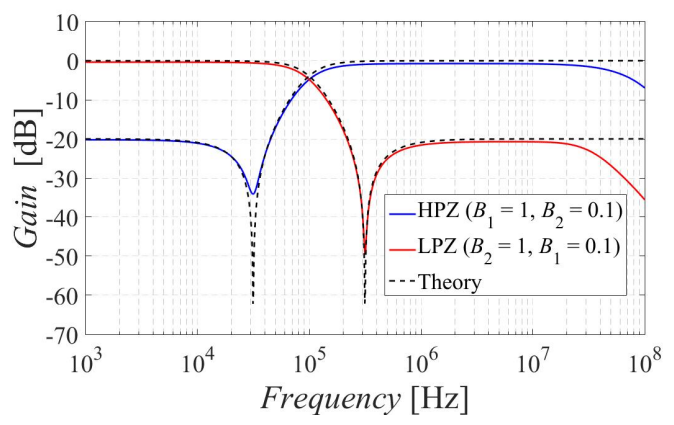

Fig. 8. Illustration of the HPZ and LPZ functions.

\section{CONCLUSION}

In comparison to the initial filtering structure, the proposed filter offers the electronical reconfiguration of its transfer and easy operation as the filter with transfer zeros. Other abilities remain preserved as in the original topology. The ability of the electronic control of $f_{0}$ and $Q$ was tested in range $50-200 \mathrm{kHz}$ (in case of $f_{0}$ control) and $0.71-2.83$ (in case of $Q$ control). Obtained simulation results are in good agreement with the theory.

\section{REFERENCES}

[1] W. Chunhua, Z. Ling, L. Tao, "A new OTA-C current-mode biquad filter with single input and multiple outputs," International Journal of Electronics and Communications (AEÜ), vol. 62, 2008, pp. 232-234.

[2] A. Qadir, T. Altaf, "Current Mode Canonic OTA-C Universal Filter with Single Input and Multiple Outputs," In Proc. The 2nd
International Conference Electronic Computer Technology (ICECT), 2010, Kuala Lumpur, Malaysia, pp. 32-24.

[3] D. Biolek, V. Biolkova, Z. Kolka, J. Bajer, "Single-Input MultiOutput Resistorless Current-Mode Biquad," In proc. of the European Conference on Circuit Theory and Design ECCTD 2009, 2009, Antalya, Turkey, pp. 225-228.

[4] V. Chamnanphrai, W. Sa-ngiamvibool, "Electronically Tunable SIMO Mixed-mode Universal Filter using VDTAs," Przegląd Elektrotechniczny, 2017, no. 3, 2017, pp. 207-211

[5] M. Kumngern, "Multiple-input single-output current-mode universal filter using translinear current conveyors," Journal of Electrical and Electronics Engineering Research, vol. 3, no. 9, 2011, pp. 162-170.

[6] W. Jaikla, S. Siripongdee, P. Suwanjan, "MISO current-mode biquad filter with independent control of pole frequency and quality factor," Radioengineering, vol. 21, no. 3, 2012, pp. 886-891.

[7] R. Tomar, S. Singh, D. Chauhan, "Current Processing Current Tunable Universal Biquad Filter Employing Two CCTAs and Two Grounded Capacitors," Circuits and Systems, vol. 4, no. 6, 2013, pp 443-450.

[8] A. Chaichana, M. Kumngern, W. Jaikla, "Electronically Tunable Versatile Current-Mode MISO Universal Filter Including Minimum Component Count Circuits," In Proc. The 11th International Conference Electrical Engineering/Electronics, Computer, Telecommunications and Information Technology (ECTI-CON), 2014, Nakhon Ratchasima, Thailand, pp. 1-4.

[9] A. Ü. Keskin, E. Hancioglu E, "Current mode multifunction filter using two CDBAs," International Journal of Electronics and Communications (AEÜ), vol. 59, issue 8, 2005, pp. 495-498.

[10] A. M. Soliman, "Current mode filters using two output inverting CCII,” Int. J. Circ. Theor. Appl., vol. 36, 2008, pp. 875-881.

[11] R. Sotner, N. Herencsar, J. Jerabek, R. Prokop, A. Kartci, T. Dostal, K. Vrba, "Z-Copy Controlled-Gain Voltage Differencing Current Conveyor: Advanced Possibilities in Direct Electronic Control of First-Order Filter," Elektronika Ir Elektrotechnika, vol. 20, no. 6, 2014, pp. 77-83.

[12] R. Sotner, J. Jerabek, N. Herencsar, R. Prokop, K. Vrba, T. Dostal, "Resistor-less First- Order Filter Design with Electronical Reconfiguration of its Transfer Function," In Proc. of the 24th International Conference Radioelektronika 2014. Bratislava, Slovakia, 2014. pp. 63-66.

[13] R. Sotner, J. Petrzela, J. Jerabek, T. Dostal, "Reconnection-less OTAbased Biquad Filter with Electronically Reconfigurable Transfers," Elektronika Ir Elektrotechnika, vol. 21, no. 3, 2015, pp. 33-37.

[14] J. Petrzela, R. Sotner, "Systematic design procedure towards reconfigurable first-order filters," In 24th International Conference radioelektronika 2014, Bratislava, Slovak Republic, 2014. pp. 1-4.

[15] R. Sotner, J. Petrzela, J. Jerabek, K. Vrba, T. Dostal, "Solutions of Reconnection-less OTA-based Biquads with Electronical Transfer Response Reconfiguration,” In Proc. of 25th International Conference Radioelektronika 2015, Pardubice, Czech Republic, 2015. pp. 40-45.

[16] J. Jerabek, R. Sotner, K. Vrba, "Electronically Adjustable TripleInput Single-Output Filter with Voltage Differencing Transconductance Amplifier," REV ROUM SCI TECH- EL, vol. 59, no. 2, 2014, pp. 163-172.

[17] R. Sotner, N. Herencsar, J. Jerabek, R. Prokop, A. Kartci, T. Dostal, K. Vrba, "Z-Copy Controlled-Gain Voltage Differencing Current Conveyor: Advanced Possibilities in Direct Electronic Control of First-Order Filter," ELEKTRONIKA IR ELEKTROTECHNIKA, vol. 20, 2014, pp. 77-83.

[18] J. Jerabek, J. Koton, R. Sotner, K. Vrba, “Adjustable band-pass filter with current active elements: two fully-differential and single-ended solutions," Analog integrated circuits and signal processing, vol. 74, 2013, pp. 129-139.

[19] J. Jerabek, R. Sotner, J. Polak, K. Vrba, T. Dostal, Reconnection-Less Electronically Reconfigurable Filter with Adjustable Gain Using Voltage Differencing Current Conveyor, ELEKTRONIKA IR ELEKTROTECHNIKA, vol. 22, no. 6, 2016, pp. 39-45. 